\title{
Medical Management of Thyroid Ectopia: Report of Three Cases
}

\author{
Deep Dutta, Manoj Kumar, Anubhav Thukral, Dibakar Biswas, Rajesh Jain, Sujoy Ghosh, \\ Satinath Mukhopadhyay, Subhankar Chowdhury \\ IPGMER \& SSKM Hospital, Department of Endocrinology \& Metabolism, Bose Road, Calcutta, India
}

\begin{abstract}
Thyroid ectopia (TE) is an embryological aberration of the thyroid gland migration most commonly observed in the lingual region followed by the sublingual, hyoid, and mediastinal regions. TE is often complicated by local compressive symptoms resulting in dysphagia, dysphonia, and dyspnea. Surgical removal of TE is frequently complicated by difficulties in intubation, increased perioperative bleeding, and severe primary hypothyroidism; on the other hand, I131 ablation is limited by high doses needed and the concern for long-term effects especially in children. We report three children with TE who all presented with compressive symptoms and were managed conservatively with levothyroxine resulting in resolution of compressive symptoms and favorable outcomes. Levothyroxine supplementation is effective and has an important role in managing $T E$, not only in correcting the associated hypothyroidism but also in resolving the associated compressive symptoms by reducing the size of the ectopic thyroid tissue.

Key words: Thyroid ectopia, lingual thyroid, submandibular thyroid, thyroglossal cyst thyroid, dual ectopic thyroid, levothyroxine
\end{abstract}

Conflict of interest: None declared

Received: 25.05 .2013

Accepted: 02.06 .2013

\section{Introduction}

Thyroid ectopia (TE) is an embryological aberration of thyroid migration characterized by presence of thyroid tissue at sites other than its normal location, most commonly in the lingual region (90\%; incidence 1:4000-1:10000), followed by the sublingual, hyoid/pre-laryngeal, and mediastinal regions $(1,2)$. Other rare sites include the pharynx, oesophagus, trachea, lung, heart, breast, duodenum, mesentery, and adrenal gland $(1,2,3)$. Observed most commonly in children and adolescents (male/female $=4 / 1$ ), TE is usually functionally incapable of meeting physiologic requirements resulting in hypothyroidism in $33-62 \%$ of these individuals (4). TE in the lingual, sublingual or laryngeal region may present with localized swelling and compressive symptoms resulting in dysphagia, dysphonia, and dyspnea often necessitating surgical removal which is frequently complicated by difficult intubation and increased peri-operative bleeding (5). We present three cases of TE with compressive symptoms all managed conservatively with favorable outcomes.

\section{Case 1}

An 8-year-old boy (height $122 \mathrm{~cm}$; 25-50th percentile; weight $20.5 \mathrm{~kg}$; 25-50th percentile) presented with snoring which had started at age 5 years and had increased over time. Complaints of dysphagia and odynophagia had started six months ago, at which time the patient was detected to have a mass $(3 X 2 \mathrm{~cm}$ reddish swelling with smooth surface; Figure 1a) at the base of his tongue, demonstrating an increased uptake on $99 \mathrm{mT}$ c scan and being consistent with lingual thyroid. No uptake was noted in the thyroid bed (Figure 1b). Ultrasonography (USG) of the neck 
revealed absence of thyroid tissue in the normal position in the neck and confirmed the presence of lingual thyroid. Hormonal evaluation revealed a state of subclinical hypothyroidism (Table 1). Levothyroxine, administered in a dose of $75 \mathrm{mcg} / \mathrm{d}$ for one year, resulted in reduction of the swelling along with resolution of the dysphagia and odynophagia (Figure 1c). Levothyroxine was continued in a dose of $50 \mathrm{mcg} / \mathrm{d}$.

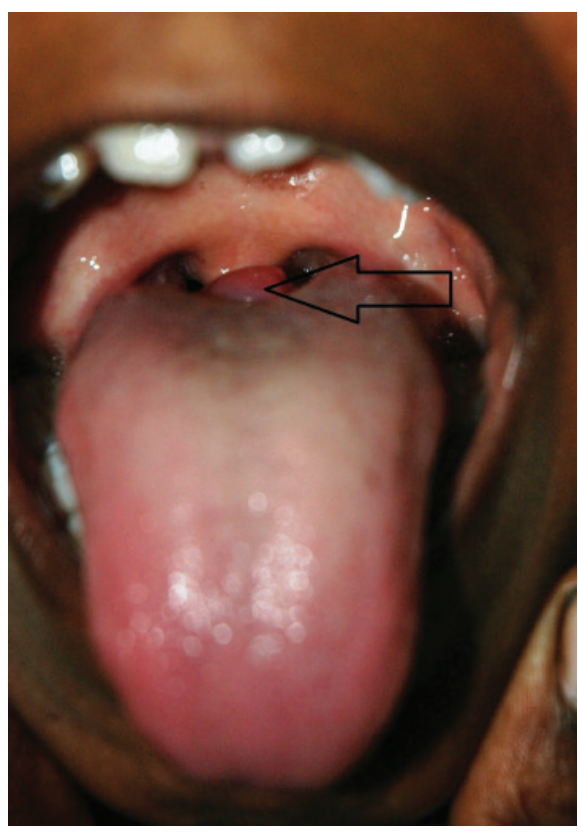

Figure 1a. Oral examination of Case 1 showing swelling at the base of the tongue (black arrow) suggestive of lingual thyroid

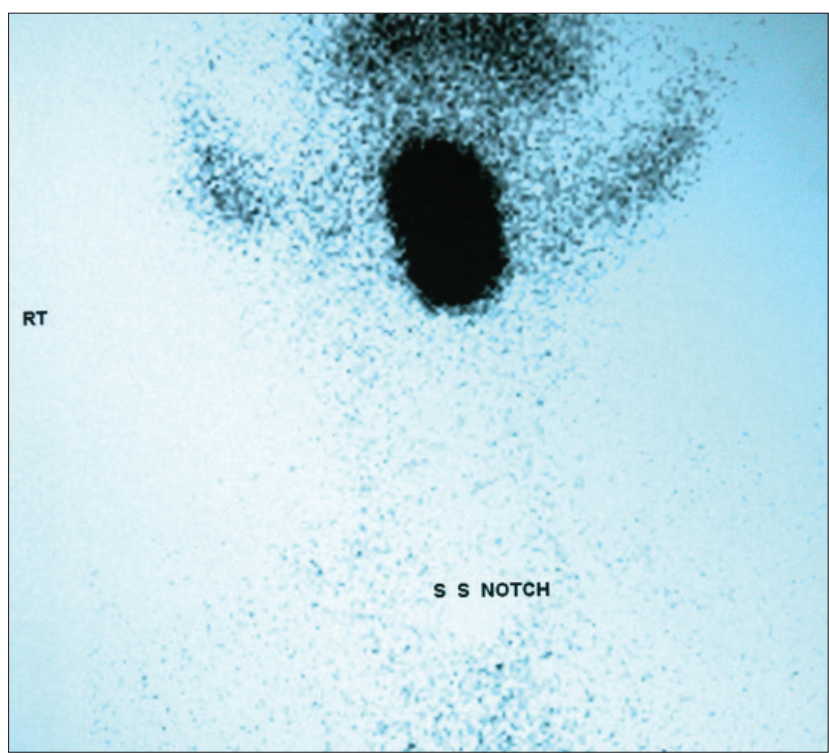

Figure 1b. Sodium pertechnetate scan showed increased $99 \mathrm{mT}$ c uptake at the base of the tongue, consistent with lingual thyroid, without any uptake in the thyroid bed in Case 1

\section{Case 2}

An 18-month-old girl patient (height $70 \mathrm{~cm}$; 5-10th percentile; weight $9.5 \mathrm{~kg} ; 10-25^{\text {th }}$ percentile) presented with complaints of poor feeding and of a swelling in the submandibular region, which moved with deglutition, noted 6 months ago (Figure 2a). The swelling was detected to be a $4 X 3 \mathrm{~cm}$ mass at the base of the tongue which showed increased uptake on 99mTc scan, consistent with lingual thyroid, without any uptake in thyroid bed (Figure 2b). The patient was also shown to have primary hypothyroidism (Table 1). Following one year of levothyroxine therapy at $50 \mathrm{mcg} / \mathrm{d}$ led to resolution of feeding problems along with a decrease in the size of the swelling.

\section{Case 3}

Primary hypothyroidism was diagnosed in a 5.5-year-old girl patient (height $105 \mathrm{~cm}$; 25th percentile; weight $17 \mathrm{~kg}$; 25-50th percentile) who presented with complaints of dysphagia, poor feeding, constipation, and dry skin in the past six months and a midline neck swelling moving with deglutition noted at age 3 years (Figure 3a). The patient had an increased 99mTc uptake suggestive of functional thyroid tissue in a thyroglossal cyst. A second area of uptake was noted in the submandibular region along with normal uptake in the thyroid bed (Figure 3b). These findings were confirmed by USG (Table 1). A diagnosis of dual ectopic thyroid (thyroglossal cyst and submandibular region) with eutopic thyroid was made. Symptoms subsided and dysphagia resolved with levothyroxine given in a dose of $50 \mathrm{mcg} / \mathrm{d}$ and increased to $75 \mathrm{mcg} / \mathrm{d}$ over nine months.

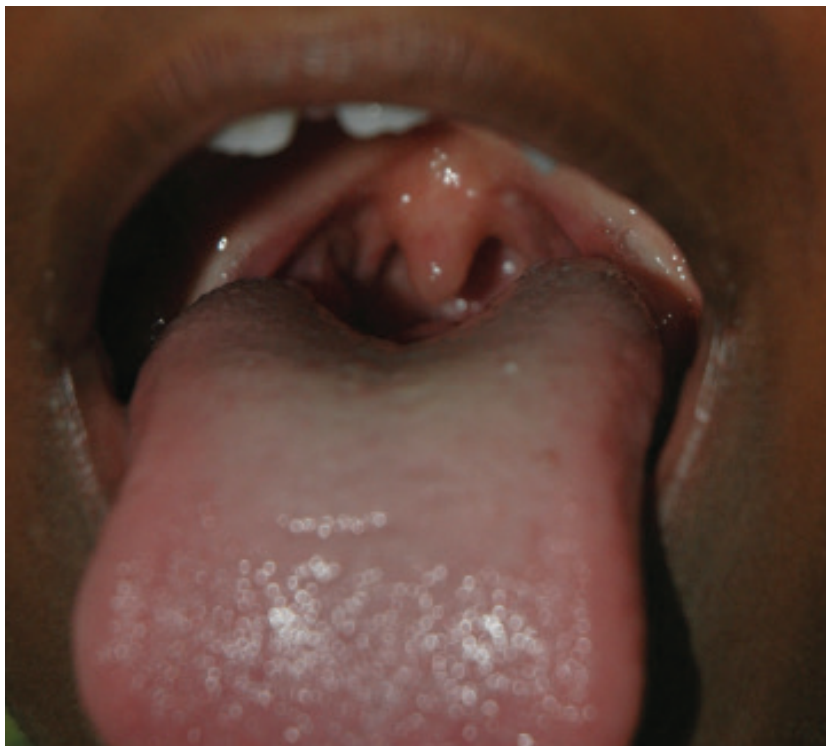

Figure 1c. Significant reduction in the size of lingual thyroid following 1 year of levothyroxine therapy 


\section{Discussion}

Aberrant descent of thyroid anlage from the floor of the primitive hypopharynx is the cause for TE and the associated absence of eutopic thyroid in $\sim 70 \%$ of the cases $(6,7,8)$. In our series of three patients, eutopic thyroid was present in only one case. Lingual thyroid was documented in two patients, and oral examination played an important role in its diagnosis. Any patient with a midline swelling in the head and neck region, below the base of tongue should undergo thyroid scintigraphy to rule out TE. Thyroglossal cysts, which are remnants of the thyroglossal duct are the most common midline neck mass in childhood (>75\%) with $35-70 \%$ containing thyroid tissue $(9,10)$. Hence, thyroid scintigraphy is mandatory in the evaluation of a thyroglossal cyst, especially when solid tissue is palpable or documented on imaging. Malignancy is rare in thyroglossal cysts (found in $<1 \%$ cases) and is almost always papillary carcinoma (11).

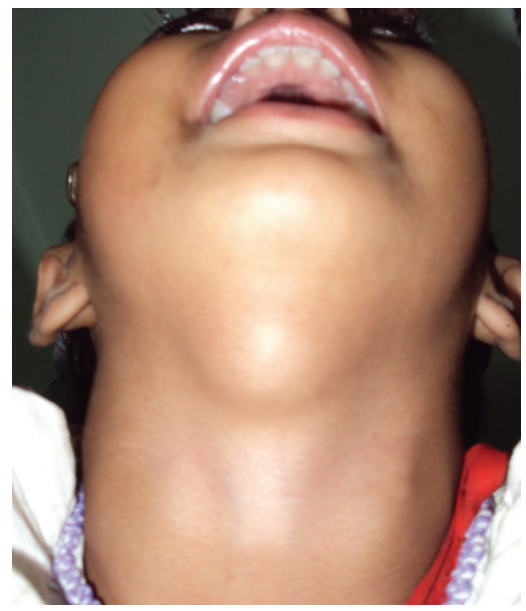

Figure 2a. Swelling in the submandibular region externally along with visibility at the root of the tongue suggestive of lingual thyroid

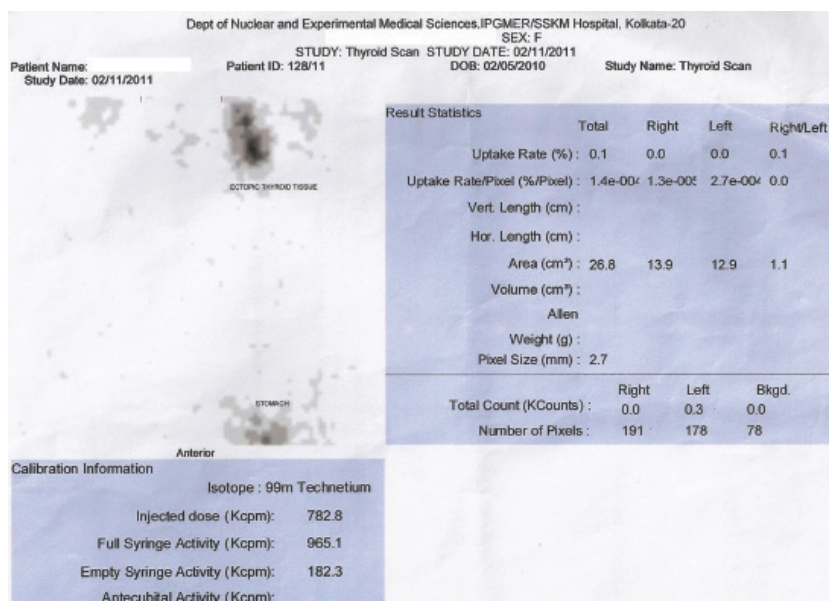

Figure $\mathbf{2 b}$. Sodium pertechnetate scan showed increased $99 \mathrm{mT}$ c uptake in the region of swelling suggestive of lingual thyroid, without any uptake in the thyroid bed in Case 2
Computed tomography (CT) and magnetic resonance imaging (MRI) are helpful in better anatomic delineation of the lesion, however are not routinely required for diagnosis since the same information can be obtained by clinical examination, thyroid scintigraphy and USG. Use of CT/MRI may be limited to difficult cases where surgical removal is contemplated.

Presence of two ectopic foci of thyroid tissue in the same patient (dual ectopia) is extremely rare with only a few isolated reports $(12,13)$. In most patients of dual ectopia, one of the foci is usually lingual/sublingual thyroid and the other is subhyoid/ suprahyoid thyroid $(12,13)$. Presence of dual ectopia along with a eutopic thyroid as observed in Case 3 is even rarer, with perhaps only a single report to date (8).

TE carries a low risk of malignancy $(<1 \%)$ and this is a point in favor of conservative management $(8,14)$. Levothyroxine treatment is usually warranted for several months before contemplating for alternatives. 1131 ablation is increasingly

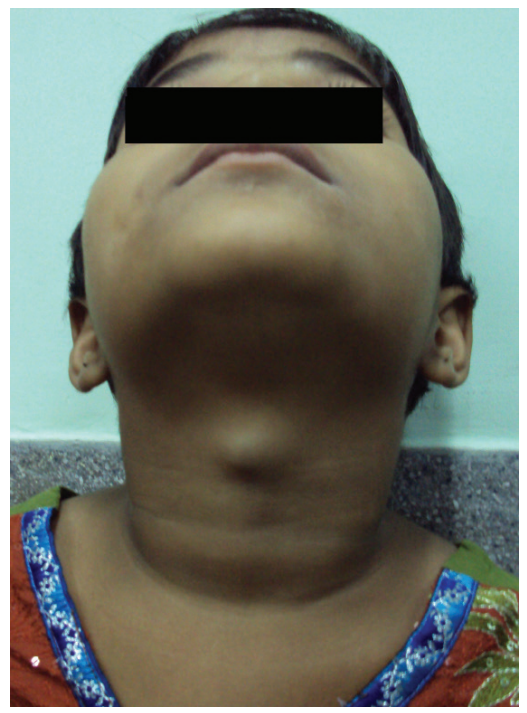

Figure 3a. Midline cystic swelling superior to the thyroid cartilage with tongue protrusion suggestive of thyroglossal cyst in Case 3

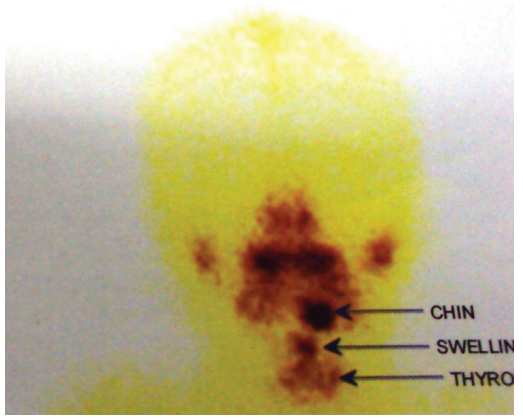

Figure $\mathbf{3 b}$. Sodium pertechnetate scan showed increased 99mTc uptake in the region of the thyroglossal cyst suggestive of functional thyroid tissue in the cyst, a second area of uptake in the submandibular/chin region along with normal uptake in the thyroid bed suggestive of presence of eutopic thyroid in Case 3 
Dutta D et al.

Medical Management of Thyroid Ectopia

Table 1. Results of biochemical evaluation, thyroid scan, and neck ultrasonography in the patients

\begin{tabular}{|c|c|c|c|c|c|c|}
\hline & Diagnosis & fт3/T3 & fT4/T4 & TSH (mU/mL) & $\begin{array}{c}\text { Anti-TPO } \\
\text { Ab (U/L) }\end{array}$ & Neck ultrasonography \\
\hline Case1 & Lingual thyroid & $-1-$ & $-/ 8.8$ & 9.6 & 11 & $\begin{array}{l}31 \mathrm{X} 22 \mathrm{~mm} \text { mass noted at the base of the tongue with increased } \\
\text { vascularity on Doppler; thyroid tissue absent in at the eutopic site }\end{array}$ \\
\hline Case2 & Lingual thyroid & $-/-$ & $0.83 /-$ & 23 & 15 & $\begin{array}{l}41 X 33 \mathrm{~mm} \text { mass noted at the base of the tongue with increased } \\
\text { vascularity with certain areas touching the opposite pharyngeal } \\
\text { wall; thyroid tissue absent at eutopic site }\end{array}$ \\
\hline Case3 & $\begin{array}{l}\text { Dual ectopic } \\
\text { thyroid with } \\
\text { normally located } \\
\text { thyroid gland }\end{array}$ & $3.1 /-$ & $0.71 /-$ & 69 & 108 & $\begin{array}{l}\text { Normally located thyroid with hypoplastic right and left lobes; } \\
22 \mathrm{X} 18 \mathrm{~mm} \text { midline cyst without any solid component with thin wall } \\
\text { noted superior to thyroid; ill-defined } 21 \mathrm{X} 14 \mathrm{~mm} \text { isoechoic mass } \\
\text { noted in the submandibular region }\end{array}$ \\
\hline
\end{tabular}

being shown to have a beneficial role in managing compressive symptoms of TE in hyperthyroid, euthyroid, and hypothyroid individuals $(15,16)$. Limitations of 131 therapy include the need for high doses to induce regression ( $20 \mathrm{mCi}$ or more), especially in euthyroid and hypothyroid individuals. 1131 therapy is generally avoided in children and young adults due to its potential unknown long-term effects $(15,16,17)$. Surgery should be reserved for patients not responding to levothyroxine treatment and those presenting with severe compressive/obstructive symptoms or bleeding.

To conclude, it may be said that levothyroxine supplementation has an important role in managing TE, not only in treating hypothyroidism but also in resolution of its compressive symptoms by reducing the size of the ectopic gland.

\section{References}

1. Chanin LR, Greenberg LM. Pediatric upper airway obstruction due to ectopic thyroid: classification and case reports. Laryngoscope 1988;98:422-427.

2. Porqueddu M, Antona C, Polvani G, Pompilio G, Cavoretto D, Gianolli L, Arena V, Sala A, Biglioli P. Ectopic thyroid tissue in the ventricular outflow tract: embryologic implications. Cardiology 1995;86:524-526.

3. Toso A, Colombani F, Averono G, Aluffi P, Pia F. Lingual thyroid causing dysphagia and dyspnoea. Case reports and review of the literature. Acta Otorhinolaryngol Ital 2009;29:213-217.

4. Yoon JS, Won KC, Cho IH, Lee JT, Lee HW. Clinical characteristics of ectopic thyroid in Korea. Thyroid 2007;17:1117-1121.

5. Mussak EN, Kacker A. Surgical and medical management of midline ectopic thyroid. Otolaryngol Head Neck Surg 2007;136:870-872
6. De Felice M, Di Lauro R. Thyroid development and its disorders: genetics and molecular mechanisms. Endocr Rev 2004;25:722746.

7. Baik SH, Choi JH, Heung-Man L. Dual ectopic thyroid. Eur Arch Otorhinolaryngol 2002;259:105-107.

8. Kumar Choudhury B, Kaimal Saikia U, Sarma D, Saikia M, Dutta Choudhury S, Barua S, Dewri S. Dual ectopic thyroid with normally located thyroid: a case report. J Thyroid Res 2011;2011:159703. Epub 2011 Jun 16

9. Tunkel DE, Domenech EE. Radioisotope scanning of the thyroid gland prior to thyroglossal duct cyst excision. Arch Otolaryngol Head Neck Surg 1998;124:597-599.

10. McHenry CR, Danish R, Murphy T, Marty JJ. Atypical thyroglossal duct cyst: a rare cause for a solitary cold thyroid nodule in childhood. Am Surg 1993;59:223-228.

11. Weiss SD, Orlich CC. Primary papillary carcinoma of a thyroglossal duct cyst: report of a case and literature review. $\mathrm{Br}$ J Surg 1991;78:87-89.

12. Sood A, Sood V, Sharma DR, Seam RK, Kumar R. Thyroid scintigraphy in detecting dual ectopic thyroid: a review. Eur $\mathrm{J}$ Nucl Med Mol Imaging 2008;35:843-846.

13. Misaki T, Koh T, Shimbo S, Kasagi K, Konishi J. Dual-site thyroid ectopy in a mother and son. Thyroid 1992;2:325-327.

14. Jarvis JF. Lingual thyroid: a report of three cases and discussion. S Afr Med J 1969;43:8-12.

15. Jacob MJ, Ravina M. A rare case of lingual thyroid with hyperthyroidism: A case report and review of the literature. Indian J Endocrinol Metab 2012;16:441-443.

16. Iglesias P, Olmos-García R, Riva B, Díez JJ. lodine 131 and lingual thyroid. J Clin Endocrinol Metab 2008;93:4198-4199.

17. Alderson DJ, Lannigan FJ. Lingual thyroid presenting after previous thyroglossal cyst excision. J Laryngol Otol 1994;108:341-343. 